\title{
Synthesis and Rheological Properties of Magnetic Chitosan Hydrogel
}

\author{
Soumia Ikhaddalene ${ }^{\star *}$, Fatima Zibouche², Alain Ponton³ ${ }^{3}$ Amar Irekti², Florent Carn³ \\ ${ }^{1}$ Laboratory of Polymer Treatment and Forming, University of M'Hamed Bougara Boumerdes, Railway Station Road, \\ 35000 Boumerdes, Algeria \\ 2 Department of Chemistry, Faculty of Sciences, University of M'Hamed Bougara Boumerdes, Railway Station Road, \\ 35000 Boumerdes, Algeria \\ 3 Laboratory of Matter and Complex Systems, University of Paris Diderot, Paris 7, CNRS, Bâtiment Condorcet, CC 7056, \\ 75205 Paris, P. O. B. 13, France \\ *Corresponding author, e-mail: iksoumia@univ-boumerdes.dz
}

Received: 04 September 2020, Accepted: 21 December 2020, Published online: 06 May 2021

\begin{abstract}
The aim of the present work is first to synthesis a magnetic chitosan hydrogel (chitosan ferrogel) using the blending method and second to study it rheological behavior. Magnetic components (maghemite particles $y-\mathrm{Fe}_{2} \mathrm{O}_{3}$ ) were synthesized via a simple chemical co-precipitation route also called Massart's procedure. Before being dispersed in chitosan network, $y$-Fe $\mathrm{O}_{3}$ particles were covered with a cationic polyelectrolyte (Polydiallyldimethylammonium chloride; PDADMAC) and the exact quantity required to cover the entire surface of maghemite particles was determined by Electrophoretic mobility. The successful functionalization of maghemite particles was confirmed by zeta potential measurement. The prepared ferrogel was gelified using glyoxal as crosslinking agent. The effect of continuous magnetic field on rheological properties of the elaborated ferrogel was studied, under controlled temperature before and after the gelation process, using a rotating rheometer fitted with a new magneto-rheological cell. Moreover the influence of iron oxide content on the gelation time of magnetic hydrogel was studied by comparing two ferrogels with different maghemite particles content. Flow and viscoelastic measurements showed that applying magnetic field facilitates the formation of a new structure (columnlike arrangements), which was confirmed by in situ optical microscopic observation. Kinetic study was investigated by mechanical spectroscopy and demonstrates that the gelation time depends on both iron oxides content and magnetic field.
\end{abstract}

\section{Keywords}

chitosan, gelation process, rheological behavior, mechanical spectroscopy

\section{Introduction}

Combining magnetic oparticles (e.g. maghemite $\gamma-\mathrm{Fe}_{2} \mathrm{O}_{3}$, magnetite $\mathrm{Fe}_{3} \mathrm{O}_{4}$ or cobalt ferrite $\mathrm{CoFe}_{2} \mathrm{O}_{4}[1]$ ) and biopolymers have attracted increasing interest since they produce highly efficient magnetic responsive hydrogels and offer more options for medicine and pharmacy such as drug delivery system [2], tissue engineering [3], cancer therapy [4] and many other applications $[5,6]$ due to their mechanism for shape change under external magnetic field. In addition they possess a remote reaction thus a non-contact action.

Magnetically responsive hydrogels also called ferrogels are usually made of suspended magnetic component (most often superparamagnetic iron oxide $\gamma-\mathrm{Fe}_{2} \mathrm{O}_{3}$ or $\mathrm{Fe}_{3} \mathrm{O}_{4}$ ) embedded within a polymeric matrix [7]. Therefore it combines in a single material the softness of the polymer network and the superparamagnetic behavior provided by the particles. Furthermore, because of the heating power that has superparamagnetic particles, magnetic hydrogels can generate heat and exhibit a quick response time when exposed to alternating magnetic field.

Liu et al. [8] reviewed the fabrication process of magnetic hydrogels and revealed the main factors capable of affecting its properties, including the type and concentration of both hydrogels and magnetic nanoparticles, size distribution and uniformity of magnetic component within the cross-linked network.

According to the kind of interactions (physical or chemical) existing between hydrogel and magnetic particles, various methods have been developed to fabricate 
magnetic hydrogel. Depending on the way of incorporating magnetic particles; mixed with a preformed hydrogel (blending method) or generated during the hydrogel formation process (in situ precipitation method). Those are called physical cross-linking methods. But if magnetic particles are functionalized with several functional groups, they generate covalent bonds with the hydrogel monomers and act as chemical cross-linkers to form hydrogel networks (grafting onto method), it is also called chemical cross-linking method [9].

The use of polysaccharide based hydrophilic systems like chitosan has created a reliable place in biological sciences, due to its unique characteristics such as good biocompatibility, biodegradability, swelling ability and hydrophilicity. It is a linear cationic polysaccharide, chemically composed of glucosamine and $\mathrm{N}$-acetyl glucosamine units. Several works have been published regarding magnetic sensitive hydrogels based chitosan e.g. Miyazaki et al. [10] designed via the in situ process magnetite $\left(\mathrm{Fe}_{3} \mathrm{O}_{4}\right)$ naoparticles in chitosan hydrogel with different cross-linking densities (glutaraldehyde solution with molar ratios ranging from 0.5 to 3.0 was added to chitosan). They found that iron oxide amount produced in chitosan hydrogel decresed with increasing cross-linking density, while their crystallite size becomes larger for such increase. However, heat generation enhanced in alternating magnetic field, indicating that this property was not controlled only by the total amount of inorganic particles.

With the same approach Hernández et al. [11] fabricated a chitosan ferrogel. They studied the effect of iron oxide nanoparticles and chitosan concentration on the rheological properties of magnetic hydrogel. The authors found that incorporation of magnetite nanoparticles increases the elastic modulus, resulting in reinforcement of the ferrogel structure. $2 \mathrm{wt} \%$ noticed to be the best concentration that reinforces the chitosan hydrogels and that was observed by the increase of viscoelastic modulus. According to this study the resulting ferrogel (with 2 wt.\% of chitosan) can be considered as potential candidates for magnetic hyperthermia treatment due to its capacity of reaching the required temperature to be effective when subjected to alternating magnetic field.

Villaminand Kitamoto [12] synthesized also a magnetic chitosan hydrogel by in situ precipitation of iron oxide nanoparticles during chitosan gel formation. They demonstrated experimentally that magnetic properties of the embedded iron oxide nanoparticles can be affected by the $\mathrm{pH}$ response of chitosan. The region of highest sensitivity of the designed magnetic hydrogel was found to be lower than $\mathrm{pH}$ 3. According to authors, the finding could be used for magnetic biosensing. Contrary to Zhang et al. [13] they used the blending method to synthesis magnetic sensitive hydrogels based polyvinly-alcohol (magnetic components were magnetite and maghemite). Resulting magnetic hydrogels showed that mechanical properties of maghemite ferrogels ( $\mathrm{PVA} / \mathrm{Fe}_{2} \mathrm{O}_{3}$ ) are much better than magnetite ferrogels (PVA/ $\left./ \mathrm{Fe}_{3} \mathrm{O}_{4}\right)$. However, magnetite PVA hydrogel exhibit good magnetic properties thus the best magnetic response.

In the present study, we propose to elaborate a magnetic chitosan hydrogel using the blending method. Maghemite $\left(\gamma-\mathrm{Fe}_{2} \mathrm{O}_{3}\right)$ particles were covered with a cationic polyelectrolyte (Polydiallyldimethylammonium chloride; PDADMAC), then dispersed in a biopolymer aqueous solution (chitosan) before the polymer being cross linked. Rheological behavior of maghemite suspensions dispersed in aqueous and jellified chitosan matrix has been investigated and discussed considering the effects of magnetic field strength. Kinetic study was investigated by mechanical spectroscopy.

\section{Experimental details}

Materials: All the following chemicals were used without further purification: Ferric chloride $\left(\mathrm{FeCl}_{3} \cdot 6 \mathrm{H}_{2} \mathrm{O}\right)$ (Sigma Aldrich, $99 \%$ ), Ferrous chloride $\left(\mathrm{FeCl}_{2} \cdot 4 \mathrm{H}_{2} \mathrm{O}\right)$ (Sigma Aldrich, $99 \%$ ), Hydrochloride acid ( $\mathrm{HCl}$ ) (VWR, $37 \%)$, Nitric acid $\left(\mathrm{HNO}_{3}\right)(\mathrm{VWR}, 69 \%)$, Ferric nitrate $\left(\mathrm{Fe}\left(\mathrm{NO}_{3}\right)_{3} \cdot 9 \mathrm{H}_{2} \mathrm{O}\right)$ (Sigma Aldrich, $98 \%$ ), ammonia $\left(\mathrm{NH}_{4} \mathrm{OH}\right)$ (Technic France, 28-30 \%), Sodium citrate $\left(\mathrm{C}_{6} \mathrm{H}_{5} \mathrm{Na}_{3} \mathrm{O}_{7} \cdot 2 \mathrm{H}_{2} \mathrm{O}\right)$ (Sigma Aldrich, $99 \%$ ), Poly(diallyldimethylammonium Chloride) (Aldrich, $40 \mathrm{wt} \%$ in $\mathrm{H}_{2} \mathrm{O}$ ) hereafter denoted as PDADMAC. Freshly prepared solutions were used in all experiments.

Chitosan was provided by Aldrich with a deacetylation percentage of $81 \%$ defined by FTIR spectroscopy [14]. Acetic acid was supplied by Merck (99\%).

Synthesis: First, ferrofluid containing citrated maghemite particles was synthesized using the iron salts alkaline co-precipitation route in water, also called Massart's process [15]. Acidic aqueous solution $(\mathrm{HCl}=0.26 \mathrm{M})$ of ferrous $(0.4 \mathrm{M})$ and ferric $(0.4 \mathrm{M})$ chloride mixed in 1:2 molar ratio was prepared in contact with air. $71.5 \mathrm{ml}$ of concentrated ammonia solution $(11 \mathrm{M})$ was then quickly added into acidic solution with vigorous stirring using a mechanical stirrer during $30 \mathrm{~min}$. The precipitate consisting of anionic magnetite was isolated with a magnet, and then stirred in nitric acid solution (1.9 M). Magnetite particles were oxidized to maghemite at $90{ }^{\circ} \mathrm{C}$ by ferric nitrate $(1.6 \mathrm{M})$. The obtained 
maghemite particles were washed three times with acetone and twice with ether, then scattered in $71 \mathrm{ml}$ of ultrapure water. Finally colloidal dispersion of maghemite particles was stabilized with $7 \times 10^{-3} \mathrm{M}$ of sodium citrate.

Preparation of chitosan solutions: Chitosan was dried in the oven until a constant weight was observed. Then five solutions containing different concentrations ranging between 0.5 and $2.0 \mathrm{wt} \%$ were prepared by dissolving chitosan powder in $15 \mathrm{ml}$ of acetic acid solution $(0.1 \mathrm{M})$.

Chitosan hydrogels: Three chitosan hydrogels were prepared by crosslinking chitosan solutions $1.3 \mathrm{wt} \%-$ $1.5 \mathrm{wt} \%-1.7 \mathrm{wt} \%$ with $20 \mu \mathrm{l}$ of glyoxal, under a mechanical stirrer for $5 \mathrm{~min}$.

Functionalization of $\gamma-\mathrm{Fe}_{2} \mathrm{O}_{3}$ with PDADMAC: Since citrated maghemite particles cannot be dispersed homogeneously in chitosan, their surface was modified with a cationic polyelectrolyte Poly(diallyldimethylammonium chloride) PDADMAC before being introduced in chitosan aqueous solution.

The exact quantity needed to cover the entire surface of maghemite particles with PDADMAC was determined by electrophoretic mobility using Laser Doppler Velocimetry (LDV). Ten samples with different PDADMAC/Particles ratios were prepared by mixing $0.01 \mathrm{v} / \mathrm{v} \%$ of maghemite particles with different concentrations of PDADMAC varying from 0.005 to $0.1 \mathrm{~g} / \mathrm{L}$. Maghemite particles $\left(\gamma-\mathrm{Fe}_{2} \mathrm{O}_{3}\right)$ and functionalized particles $\left(\gamma-\mathrm{Fe}_{2} \mathrm{O}_{3}+\right.$ PDADMAC) are hereafter denoted as bare particles and covered particles, respectively.

The mixture of $0.7 \mathrm{v} / \mathrm{v} \%$ of $\gamma-\mathrm{Fe}_{2} \mathrm{O}_{3}$ and $4.2 \mathrm{~g} / \mathrm{L}$ of PDADMAC was stirred for $5 \mathrm{~min}$ then allowed to stand at room temperature. The successful functionalization of $\gamma-\mathrm{Fe}_{2} \mathrm{O}_{3}$ and the positive surface charge of the covered particles were confirmed by Zeta potential measurements using the Nanosizer Malvern instrument operating with a $\mathrm{He}-\mathrm{Ne}$ laser of $633 \mathrm{~nm}$.

Chitosan ferrogels: Two chitosan ferrogels having different iron oxides content were prepared. Briefly $1.579 \mathrm{~g}$ and $2.256 \mathrm{~g}$ of citrated maghemite covered respectively with $0.105 \mathrm{~g}$ and $0.150 \mathrm{~g}$ PDADMAC, were stirred mechanically for $5 \mathrm{~min}$, and then dispersed in $5 \mathrm{~g}$ of chitosan solution $1.3 \mathrm{wt} \%$. Before being coagulated with $20 \mu \mathrm{l}$ of glyoxal, all components were mixed for another $5 \mathrm{~min}$.

\section{Rheological characterization}

The influence of magnetic field on rheological properties and the effect of iron oxides content on the gelation process of chitosan ferrogel were all studied using a mechanical spectroscopy.
Flow and viscoelastic measurements were performed under continuous magnetic field and controlled temperature, in a designed rotating rheometer fitted with a new magneto-rheological cell, described in details in [16]. Rheological properties of the tested samples were established in a cone-plate system, plate made of a transparent glass and titanium cone of $60 \mathrm{~mm}$ diameter, 1 cone angle and a gap of $0.052 \mathrm{~mm}$. A vertical magnetic field direction was applied during the test with different intensities: $13.02 \mathrm{kA} / \mathrm{m}-19.32 \mathrm{kA} / \mathrm{m}$ and $25.63 \mathrm{kA} / \mathrm{m}$. For the visualization system a camera was placed under the plate geometry. The sample volume used in the tests was $2 \mathrm{ml}$. Flow curves in the range of shear rates $1 \mathrm{~s}^{-1}<\gamma<2000 \mathrm{~s}^{-1}$ were established. The measurement was conducted in the linear range of viscoelasticity at constant frequency of $1 \mathrm{~Hz}$ and amplitude interval of 0.0001-1000. For frequency sweeps tests, they were executed under a constant strain of 1, with a frequency range varying between 0.01 to $100 \mathrm{~Hz}$. All measurements were carried out at room temperature.

A Kinetic study of chitosan gel and ferrogel gelation was conducted by rheology. Characteristics of the prepared gels were experimentally determined by successive cycles (repeated 300 times) of frequency sweeps measurements varying from $0.1 \mathrm{~Hz}$ to $1 \mathrm{~Hz}$ with a step of $0.15 \mathrm{~Hz}$. Gelation kinetics measurement began after 7 min of reaction (5 min of mechanical stirring and 2 min for setting up the rheological experiment).

According to Winter criterium [17] viscous and elastic modulus have a power law behavior with auto-similarity properties during gel formation. So the resulting intersection point of the different curves $\left(G^{\prime \prime} / G^{\prime}\right.$ as a function of time for different frequencies) was used to determine the time of gelation "tg" applying a simple projection of the crossing curves on $y$-axis. It is also possible, to characterize the structure at the gelation time by determining the relaxation exponent $\Delta$.

Ferrogels stiffness $S$ could be deduced from Eq. (1) and Eq. (2) by knowing the values of $G^{\prime}$ and $G^{\prime \prime}$ at $t g$.

$$
\begin{aligned}
& G^{\prime}(\omega)=\frac{\pi S \omega^{\Delta}}{2 \Gamma(\Delta) \sin \left(\frac{\Delta \pi}{2}\right)} \\
& G^{\prime \prime}(\omega)=\frac{\pi S \omega^{\Delta}}{2 \Gamma(\Delta) \cos \left(\frac{\Delta \pi}{2}\right)}
\end{aligned}
$$

$\Gamma$ is the gamma function and $\omega$ is the pulsation for dynamic measurements.

Combining Eq. (1) and Eq. (2) we obtain the following relation at $\operatorname{tg}$ : 
$\tan \delta=\frac{G^{\prime \prime}}{G^{\prime}}=c s t=\tan \left(\frac{\Delta \pi}{2}\right)$

where $\delta$ represents the phase shift between the stress and the strain during oscillation experiments.

\section{Results and discussion}

\subsection{Electrophoretic mobility}

Fig. 1 shows Mobility evolution as a function of the ratio (PDADMAC/Particles).

Electrophoretic mobility is the rate at which the particle moved divided by the magnitude of the electric field. So the velocity of a particle in an electric field is commonly referred to as its electrophoretic mobility.

By knowing Electrophoretic mobility we can obtain the zeta potential of the particle by applying the Henry equation Eq. (4) [18]:

$\mu=\frac{2 \varepsilon \zeta f(\kappa a)}{3 \eta}$,

where $\zeta$ denotes the zeta potential, $\mu$ the mobility, $\varepsilon$ the dielectric constant, $\eta$ the viscosity and $f(\kappa a)$ Henrys function equal to 1.5 (for small particles in aqueous media).

The zeta potential can be defined as the voltage of the edge of the double layer (positively charged by PDADMAC) covering the negatively charged particles. Increasing mobility is proportional to the increase in zeta potential according to Henry equation.

Therefore if we increase PDADMAC concentration, the particles will be more charged with the positive ions of the polyelectrolyte and the zeta potential increases to reach a constant value which corresponds to the saturation of the particles surface. No need to add more

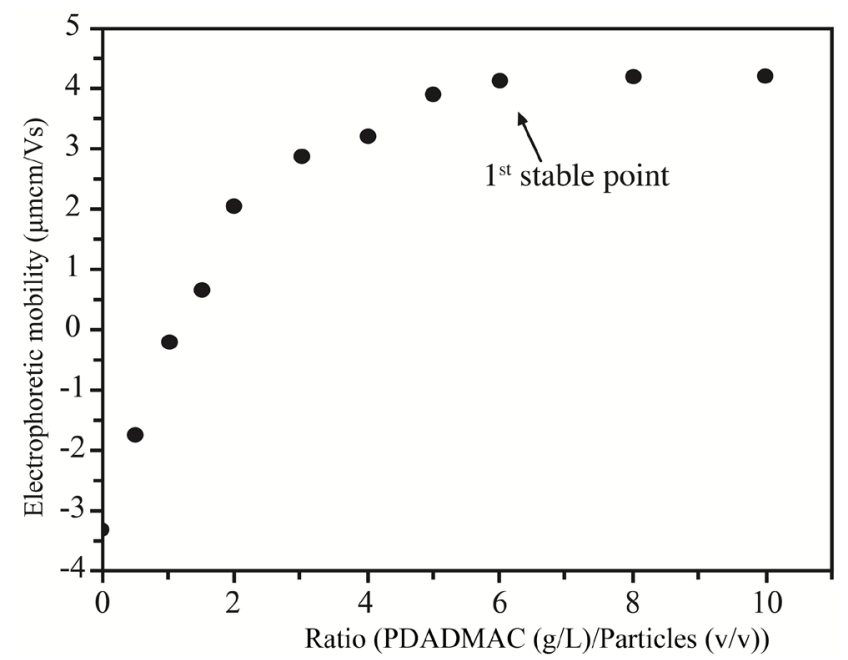

Fig. 1 Mobility evolution as function of the ratio (PDADMAC/Particles)
PDADMAC after reaching the first stable point. For this reason the best ratio was fixed to $6(0.06 \mathrm{~g} / \mathrm{L}$ PDADMAC for $0.01 \mathrm{v} / \mathrm{v} \%$ Particles).

\subsection{Zeta potential measurement}

The aqueous solution of covered particles exhibits a positive zeta potential around $60.8 \mathrm{mV}$. Covered particles tend to repeal each other as long as they have a large zeta potential. There is no tendency to aggregate.

The higher the zeta potential is the more stable are the colloids. Because typically a stable colloidal suspension should have a zeta potential more positive than $30 \mathrm{mV}$ or more negative than $-30 \mathrm{mV}$ [18], moreover the obtained positive value $(60.8 \mathrm{mV})$ means that the particles are positively charged with the ions of the polyelectrolyte PDADMAC. Our results confirm the successful functionalization of $\gamma-\mathrm{Fe}_{2} \mathrm{O}_{3}$ particles.

\subsection{Rheological results}

The general rheological behavior of bare and covered particles can be seen at Fig. 2. It is obvious that in absence of magnetic field, dispersed aqueous solution of bare particles $(0.7 \mathrm{v} / \mathrm{v} \%)$ exhibited a Newtonian behavior (for relatively high shear rate) which could be approximated using the Newton approach Eq. (5).

$\tau=\eta \dot{\gamma}$,

where $\tau$ denotes the shear stress, $\eta$ the viscosity and $\dot{\gamma}$ the shear rate.

While covered particles indicate a great resistance to flow, plus a decrease in viscosity with increasing shear rate. It has a shear thinning behavior [19]. The same figure showed that

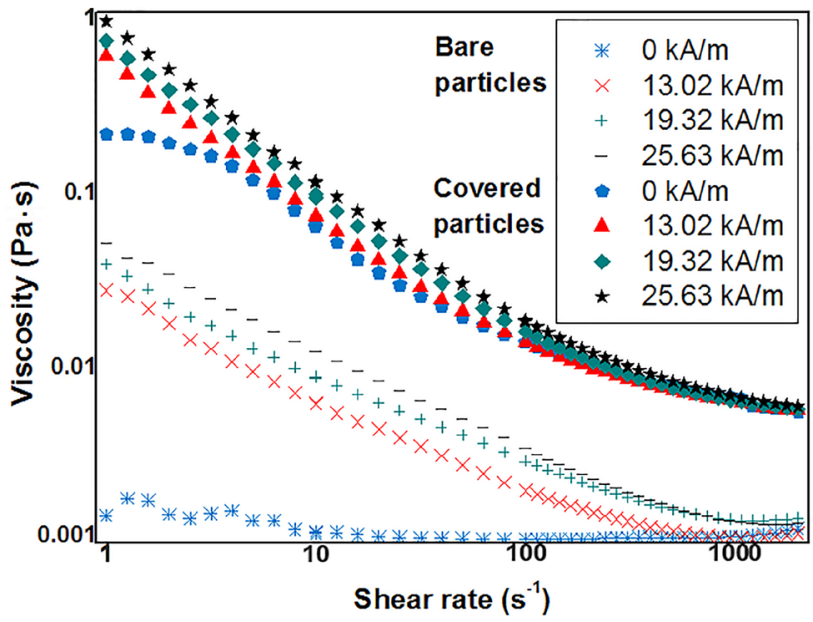

Fig. 2 Viscosity as a function of shear rate for bare $(0.7 \mathrm{v} / \mathrm{v} \%)$ and covered particles $(0.7 \mathrm{v} / \mathrm{v} \%+4.2 \mathrm{~g} / \mathrm{L}$ PDADMAC $)$ 
applying increasing magnetic field strength leads to a fluid behavior change. A deviation from Newtonian to non-Newtonian behavior was mostly expressed by bare particles and the best fit of the measured data could be obtained by Herschel-Bulkley model Eq. (6) [20]:

$\tau=\tau_{0}+k \dot{\gamma}^{n}$

with the yield stress $\tau_{0}$, the flow consistency $k$ and the power law index $n$.

Fig. 3 shows that experimental data are in good conformity with this model. Parameters of the fitting results are collected in Table 1. It is obvious that $\tau_{0}$ and $k$ increase with increasing magnetic field strength while $n$ decreased for both samples. Those values confirm the shear thinning behavior.

It can be noticed that magnetic field causes a rapid increase of viscosity at low shear rate (Fig. 2), and this can be due to the formation of particle chains caused by the dipole alignment of suspended magnetic particles. As the external magnetic field rise, the interaction between magnetic particles becomes stronger and chains begin to be longer. Eventually the resistance of fluid to flow increases as the length of the chains grows and hence leads to an increase in viscosity [21].

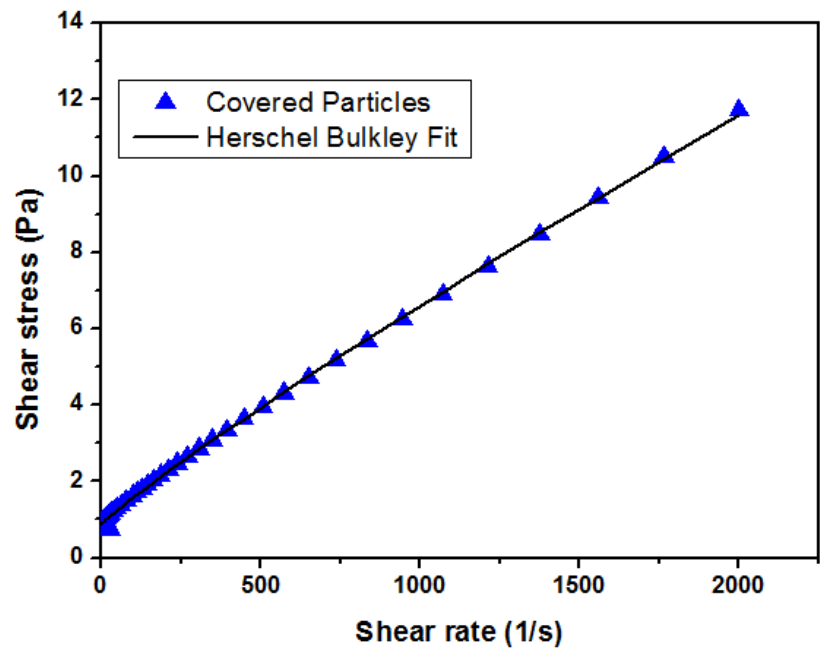

Fig. 3 Conformity of covered particles $(0.7 \mathrm{v} / \mathrm{v} \%+4.2 \mathrm{~g} / \mathrm{L}$ PDADMAC) with Herschel-Bulkley model $(H=19.32 \mathrm{kA} / \mathrm{m})$
The successive detailed process explains the phenomenon of so-called Magneto-Viscous Effect (MVE) [22]. The relative viscosity can quantify that increase in flow measurement under applying magnetic field by using a common method defined as Eq. (7) [23]:

$\mathrm{MVE}=\frac{\eta_{H}-\eta_{0}}{\eta_{0}}$

where $\eta_{H}$ and $\eta_{0}$ are the viscosities of the magnetic fluid with and without applying magnetic field $(H)$, respectively.

The Magneto-Viscous Effect variation as a function of the shear rate is plotted in Fig. 4 for bare and covered particles, respectively.

As illustrated in Fig. 4 both systems display the same MVE, but with different intensities noticed to be stronger for bare particles. This intensity would be determined by the strength of the magneto-static interaction between the particles aggregates.

It is clear that the magnitude of MVE indicates increasing values at low shear rate as magnetic field rise. This can be explained by the formation of temporal clustered structures constituted by a large number of particles aggregate aligned along the field direction. On the other hand another type of aggregate exist representing the combination particle/PDADMAC which would deform in presence of $H$ in order to minimize its free energy balanced by the bulk free energy, which tend to stretch the aggregate in the direction of $H$.

Here the energies associated to the surface tension, allow the polyelectrolyte to maintain a spherical shape for the aggregate and thus reduces aggregation [24]. This would justify the lower MVE in the second system (covered particles).

Odenbach and Raj [25] studied the change of magnetoviscous properties under the influence of particle size. The authors found that increasing the size of colloidal suspensions showed a greater MVE. While small particles lead to a negligible MVE, confirming again that adding PDADMAC to maghemite particles reduces agglomeration and leads to a slighter MVE.

Table 1 Fit parameters for bare and covered particles under different magnetic field strength

\begin{tabular}{|c|c|c|c|c|}
\hline Sample & $0 \mathrm{kA} / \mathrm{m}$ & $13.02 \mathrm{kA} / \mathrm{m}$ & $19.32 \mathrm{kA} / \mathrm{m}$ & $25.63 \mathrm{kA} / \mathrm{m}$ \\
\hline & $\tau=\eta \gamma$ & $\tau=\tau_{0}+k \gamma^{n}$ & & \\
\hline Bare particles & $\eta=1.1 \times 10^{-3} \mathrm{~Pa} \cdot \mathrm{s}$ & $\begin{aligned} \tau_{0} & =0.060 \\
k & =0.001 \\
n & =0.990\end{aligned}$ & $\begin{aligned} \tau_{0} & =0.090 \\
k & =0.001 \\
n & =0.940\end{aligned}$ & $\begin{array}{l}\tau_{0}=0.110 \\
k=0.003 \\
n=0.850\end{array}$ \\
\hline Covered particles & $\begin{array}{c}\tau=\tau_{0}+k \gamma^{n} \\
\tau_{0}=0.421 \\
k=0.011 \\
n=0.903\end{array}$ & $\begin{aligned} \tau_{0} & =0.644 \\
k & =0.012 \\
n & =0.894\end{aligned}$ & $\begin{aligned} \tau_{0} & =0.864 \\
k & =0.012 \\
n & =0.884\end{aligned}$ & $\begin{aligned} \tau_{0} & =1.064 \\
k & =0.013 \\
n & =0.804\end{aligned}$ \\
\hline
\end{tabular}



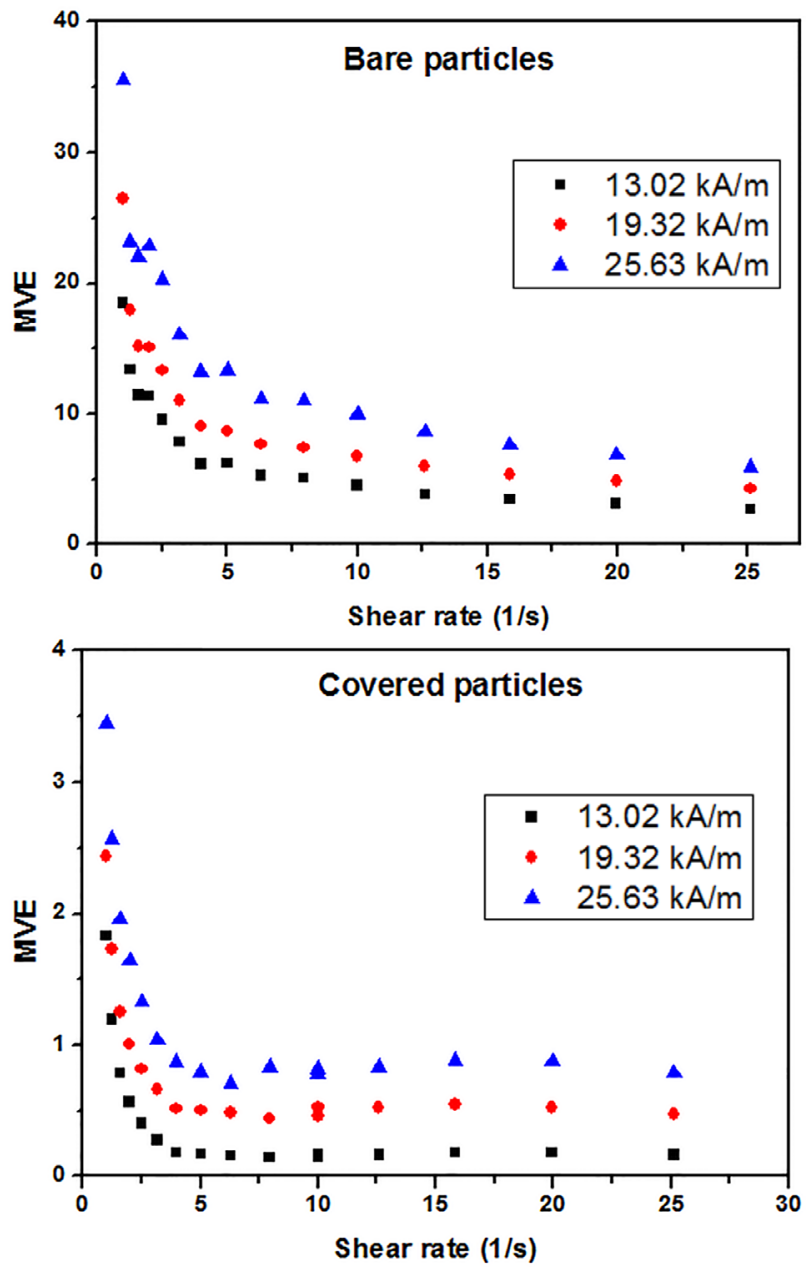

Fig. 4 The Magneto-Viscous Effect for bare particles $(0.7 \mathrm{v} / \mathrm{v} \%)$ and covered particles $(0.7 \mathrm{v} / \mathrm{v} \%+4.2 \mathrm{~g} / \mathrm{L}$ PDADMAC $)$

Chain arrangements of covered particles measured with mechanical shear at $13.02 \mathrm{kA} / \mathrm{m}$ were optically visualized using a microscopic observation (Fig. 5)

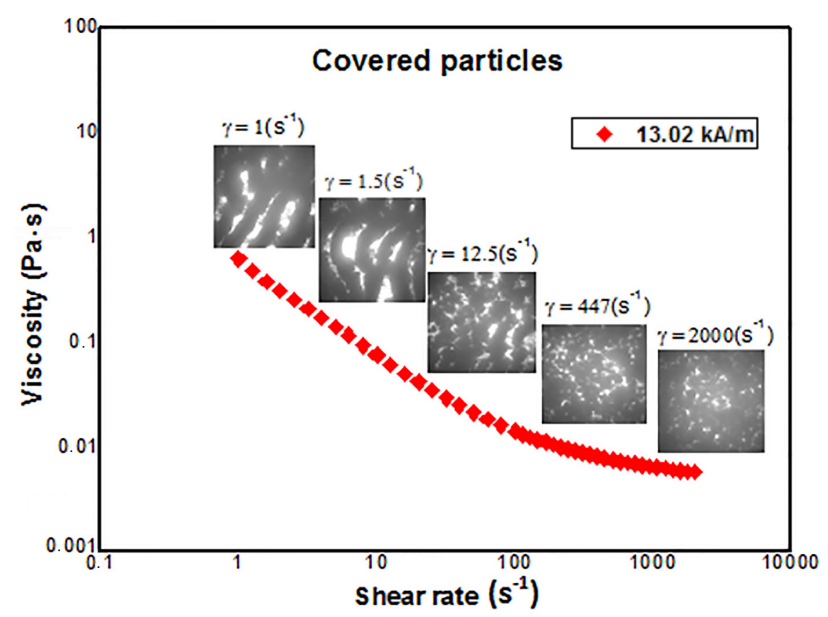

Fig. 5 Microscopic observation during flow measurement under magnetic field $(13.02 \mathrm{kA} / \mathrm{m})$ for covered particles

$(0.7 \mathrm{v} / \mathrm{v} \%+4.2 \mathrm{~g} / \mathrm{L}$ PDADMAC)
Fig. 5 shows that applying magnetic field at low shear rate causes a structural column like arrangement aligned along the field direction, while the high shear rate provoke it destruction progressively $\left(\dot{\gamma}=12.7-447-2000 \mathrm{~s}^{-1}\right)$.

From Fig. 6 it is clear that the flow curves of chitosan solutions in the concentration range $0.5-2.0 \mathrm{wt} \%$ showed a shear thinning behavior, characterized by approximately constant viscosity at low shear rate followed by a decrease in viscosity while increasing shear rate above a critical value.

This typical behavior related to entangle polymer networks was successfully fitted by the cross equation Eq. (8) $[26,27]$ :

$\eta=\eta_{\infty}+\frac{\eta_{0}-\eta_{\infty}}{1+(a \dot{\gamma})^{p}}$

where $\eta_{0}$ and $\eta_{\infty}$ are limiting viscosities at zero and infinite shear rates, $\eta_{\infty}$ was not obtained experimentally but fixed to the viscosity of water at $25{ }^{\circ} \mathrm{C} \eta_{\infty}=1 \times 10^{-3} \mathrm{~Pa} \cdot \mathrm{s}$. The parameters $a$ and $\dot{\gamma}$ are relaxation time and shear rate respectively, $p$ is an exponent.

The zero shear rate viscosity $\eta_{0}$ increases with increasing chitosan concentration (Table 2). The present results are in agreement with the values generally obtained for polymer solutions [28].

As can be seen in Fig. 6 shear rate dependence viscosity increases with increasing chitosan concentration and this is due to the fact of rising the degree of chains entanglement.

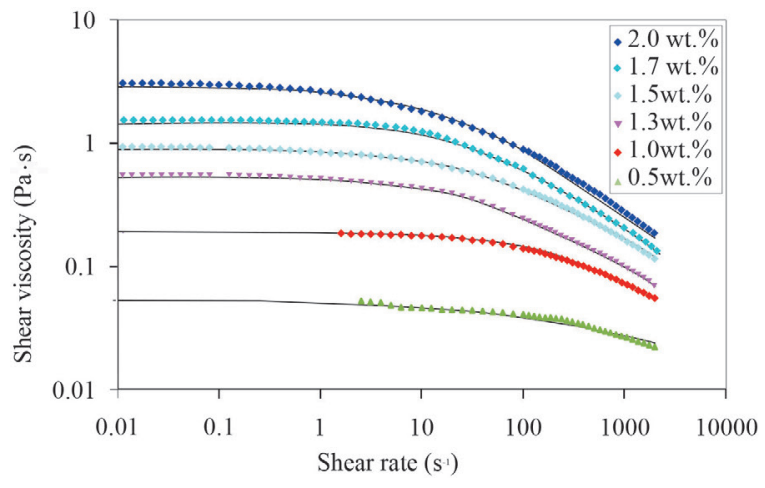

Fig. 6 Influence of concentration on the shear viscosity of chitosan solutions

Table 2 Cross model parameters $\eta_{0}, a$ and $p$ for chitosan solutions in the concentration range $0.5-2.0 \mathrm{wt} \%$

\begin{tabular}{lccc}
\hline Concentration $(\mathrm{wt} \%)$ & $\eta_{0}(\mathrm{~Pa} \cdot \mathrm{s})$ & $a\left(\mathrm{~s}^{-1}\right)$ & $p$ (dimensionless) \\
\hline 0.5 & 0.052 & $8 \times 10^{-4}$ & 0.40 \\
1.0 & 0.186 & $1 \times 10^{-3}$ & 0.53 \\
1.3 & 0.302 & $9 \times 10^{-3}$ & 0.55 \\
1.5 & 0.880 & $1 \times 10^{-2}$ & 0.57 \\
1.7 & 1.026 & $2 \times 10^{-2}$ & 0.60 \\
2.0 & 2.755 & $3 \times 10^{-2}$ & 0.64 \\
\hline
\end{tabular}


In other words increasing polymer concentration tends to restrict movement freedom of individual chains [29].

Rheological parameters of the prepared chitosan hydrogels are collected in Table 3.

Chitosan gelation is generated by deprotonation of amino groups while increasing $\mathrm{pH}$, which promotes cross-linking hydrogels. Gelation kinetics is therefore accelerated and the gelation time is reduced. This type of behavior has also been observed by Brack et al. [30]. Moreover rising polymer concentration accelerate that process and thus decrease the gelation time. This can be explained by the increase in entanglement density which leads to an increase in the probability of linking between two chitosan chains. This variation has also been observed for the same polymer network chemically crosslinked with glutaraldehyde [31].

We noticed also that at $t g$, relaxation exponent $\Delta$ increased with decreasing potential of hydrogen $\mathrm{pH}$. This behavior is due to the increase of charged part present on polymer chains when $\mathrm{pH}$ increased. In fact the more the chains are charged, the more they repel each other and reduce intermolecular hydrophobic interactions. Hydrogel structure is thus more porous and less elastic when $\mathrm{pH}$ decreases. This can be confirmed by the decrease in $S$ stiffness of the gel.

An example of viscous and elastic modulus variation is represented in Fig. 7 for a frequency of $1 \mathrm{~Hz}$ during the formation of $1.3 \mathrm{wt} \%$ of chitosan hydrogel.

Table 3 Rheological parameters of chitosan hydrogels

\begin{tabular}{lcccc}
\hline Sample & $\mathrm{pH}$ & $\operatorname{tg}(\mathrm{s})$ & $\Delta$ & $S\left(\mathrm{~Pa} \cdot \mathrm{s}^{\Delta}\right)$ \\
\hline $1.3 \%$ chitosan & 4.41 & $3550 \pm 150$ & $0.67 \pm 0.02$ & $0.43 \pm 0.01$ \\
$1.5 \%$ chitosan & 4.62 & $1380 \pm 100$ & $0.64 \pm 0.01$ & $0.90 \pm 0.01$ \\
$1.7 \%$ chitosan & 4.90 & $877 \pm 30$ & $0.58 \pm 0.01$ & $3.03 \pm 0.01$ \\
\hline
\end{tabular}

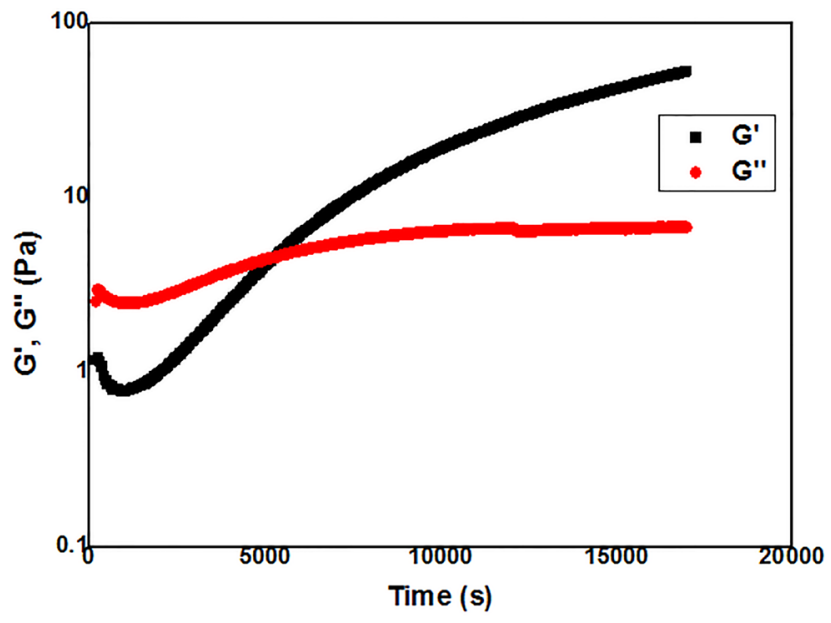

Fig. 7 Evolution of elastic modulus $\left(G^{\prime}\right)$ and viscous modulus $\left(G^{\prime \prime}\right)$ during chitosan gelation of $1.3 \mathrm{wt} \%$ chitosan solution for a frequency of $1 \mathrm{~Hz}$.
At low time values, loss modulus $G^{\prime \prime}$ which define the viscous energy dissipated by the gel (as a result of internal shear stress) was higher than the storage modulus $G^{\prime}$ that characterize elastic energy absorbed by the gel. This liquid like behavior was due to chitosan solution solubilized in acetic acid. Both moduli increased slowly to achieve a characteristic time defined as the gelation time $t g$, for which elastic and viscous moduli becomes equal. After that point $G^{\prime}$ increased to become much higher than $G^{\prime \prime}$. The finding is typical to the evolution of a viscoelastic material that move from liquid to solid state. This sol-gel transition corresponds to intermolecular bonds formation induced by chitosan deprotonation.

Fig. 8 shows flow measurement of covered particles dispersed in chitosan solution, operated under different magnetic field. The fluid exhibited the same shear thinning behavior as covered particles, except the presence of a larger static viscosity plateau. The same increase in viscosity was observed with increasing magnetic field. The behavior of our sample was demonstrated using the Herschel-Bulkley law. The flow fitted curves for different magnetic field strength $(6.71-13.02-19.32-25.63 \mathrm{kA} / \mathrm{m})$ are shown together in Fig. 9 and the obtained values of rheological parameters are listed in Table 4. Results showed increase of yield stress $\tau_{0}$ and consistency flow $k$ with decreasing the power law index $n$.

A comparison was conducted between chitosan solution $(1 \mathrm{wt} \%)$ and chitosan containing covered particles $(0.7 \mathrm{v} / \mathrm{v} \%+4.2 \mathrm{~g} / \mathrm{L}$ PDADMAC $+1 \mathrm{wt} \%$ chitosan) (Fig. 8). It was found that both have similar shear thinning behavior, with a slight viscosity variation (around $0.087 \mathrm{~Pa} \cdot \mathrm{s}$ )

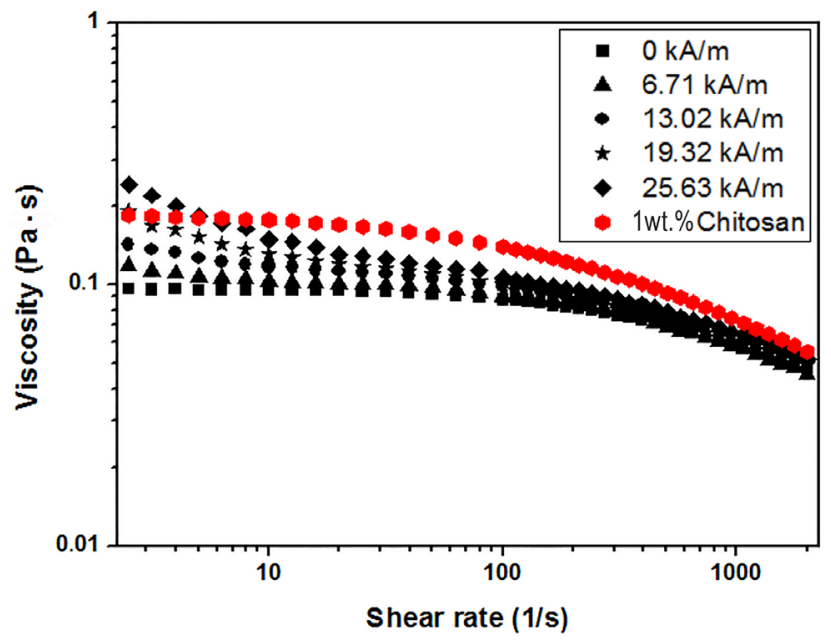

Fig. 8 Viscosity versus shear rate for chitosan alone (1 wt $\%)$ $(H=0 \mathrm{kA} / \mathrm{m})$ and covered particles dispersed in chitosan solution $(0.7 \mathrm{v} / \mathrm{v} \%+4.2 \mathrm{~g} / \mathrm{L}$ PDADMAC $+1 \mathrm{wt} \%$ chitosan) (at different $H)$ 


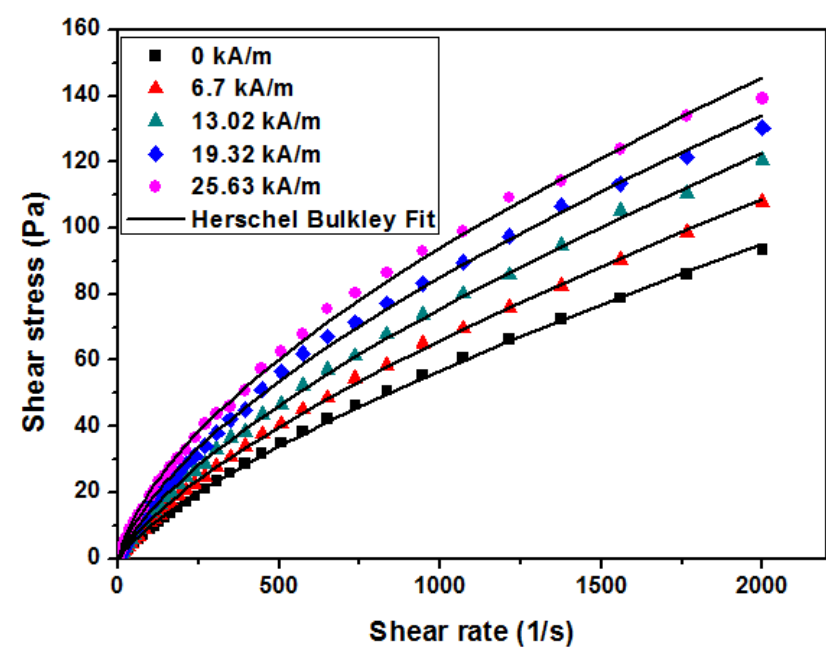

Fig. 9 Herschel-Bulkley fit curves for covered particles dispersed in chitosan $(0.7 \mathrm{v} / \mathrm{v} \%+4.2 \mathrm{~g} / \mathrm{L}$ PDADMAC $+1 \mathrm{wt} \%$ chitosan $)$ at different magnetic field strength

noticed to be higher for chiosan alone. This variation is directly related to the acidity of the medium, i.e the more acidic the medium is, the lower is the viscosity $(\mathrm{pH}=4.2$ for chitosan alone and $\mathrm{pH}=3$ for covered particles in chitosan), this phenomena correspond to the electrostatic repulsion forces present between PDADMAC and chitosan. We can deduce that rheological properties of such material depend on the variation of $\mathrm{pH}$ medium.

Amplitude sweeps: Strain or amplitude sweeps measurements were used to define the Linear Visco-Elastic (LVE) region of covered particles dispersed in chitosan, whose storage modulus and loss factor are independent of the magnitude of deformation. Fig. 10 shows the variation of elastic $G^{\prime}$ and viscous moduli $G^{\prime \prime}$ as a function of strain amplitude for the sample $(0.7 \mathrm{v} / \mathrm{v} \%+4.2 \mathrm{~g} / \mathrm{L}$ PDADMAC $+1 \mathrm{wt} \%$ chitosan) at different values of magnetic field strength and constant frequency of $1 \mathrm{~Hz}$. This variation is typical of viscoelastic material, initiated by a linear pseudo plateau followed by a sharp downturn at critical strain of 0.224 . Which is clearly represented by $G^{\prime}$ curves.

As can be seen at low strain amplitude, $G^{\prime}$ is not dependent on the strain variation, which indicates that the deformation imposed to the sample is reversible and do not cause a structural breakdown of the structure, contrary to high values of strain amplitude.

Comparing $G^{\prime}$ and $G^{\prime \prime}$ curves variation with magnetic field strength we notice that both modulus shows increasing values with increasing $H$, signifying a good magnetic field dependent rheological properties. We notice also that in absence and at lower values of field strength $(6.71 \mathrm{kA} / \mathrm{m}$ and $13.02 \mathrm{kA} / \mathrm{m}) G^{\prime \prime}$ is higher than $G^{\prime}$ and therefore liquid like behavior predominates which means that the sample displays a fluid structure and can be termed a viscoelastic liquid, while at higher values of magnetic field $(19.32 \mathrm{kA} / \mathrm{m}$ and $25.63 \mathrm{kA} / \mathrm{m})$ the situation is reversed with $G^{\prime}$ and therefore solid like behavior dominate, in this case the sample can be termed a viscoelastic solid material.

This liquid-solid transition is clarified in Fig. 11 where the variation of the ratio $G^{\prime \prime} / G^{\prime}$ was plotted as a function of magnetic field in the Linear Visco-Elastic region. The transition phase was represented by a line $\left(\left(G^{\prime \prime} / G^{\prime}\right)_{\text {LVE region }}=1.1\right)$. According to the graph, we can say that our sample is more liquid than solid at low value of the applied magnetic field $\left(\left(G^{\prime \prime} / G^{\prime}\right)_{\text {LVE region }}>1.1\right)$ with $G^{\prime \prime}>G^{\prime}$, but increasing field progressively induces the formation of a new microstructure and the sample behaves more like solid than liquid $\left(\left(G^{\prime \prime} / G^{\prime}\right)_{\text {LVE region }}<1.1\right)$ with $G^{\prime \prime}<G^{\prime}$.

Frequency sweeps: Frequency sweeps were used for gathering information in the non-destructive deformation range on the behavior and inner structure of covered particles dispersed in chitosan $(0.7 \mathrm{v} / \mathrm{v} \%+4.2 \mathrm{~g} / \mathrm{L}$ PDADMAC $+1 \mathrm{wt} \%$ chitosan).

As can be seen in Fig. 12 the frequency dependence of elastic and viscous modulus measured in the LVE region shows an enhancement of $G^{\prime}$ and $G^{\prime \prime}$ values as the magnetic field strength increased. As discussed previously in the flow measurements and strain sweeps, the applied magnetic field strengthens the microstructure of the system. Moreover at low frequencies the loss modulus found to be dominating over the storage modulus till a critical frequency $(f=4.642 \mathrm{~Hz})$ above which we notice the opposite behavior $\left(G^{\prime \prime}<G^{\prime}\right)$. At high frequencies the studied sample shows no influence under field strength.

Table 4 Herschel-Bulkley fit parameters for covered particles dispersed in chitosan at different magnetic field

\begin{tabular}{|c|c|c|c|c|c|}
\hline Sample & $0 \mathrm{kA} / \mathrm{m}$ & $6.71 \mathrm{kA} / \mathrm{m}$ & $13.02 \mathrm{kA} / \mathrm{m}$ & $19.32 \mathrm{kA} / \mathrm{m}$ & $25.63 \mathrm{kA} / \mathrm{m}$ \\
\hline & $\tau=\tau_{0}+k \gamma^{n}$ & & & & \\
\hline $0.7 \mathrm{v} / \mathrm{v} \%+4.2 \mathrm{~g} / \mathrm{L}$ PDADMAC $+1 \mathrm{wt} \%$ chitosan & $\begin{aligned} \tau_{0} & =1.202 \\
k & =0.381 \\
n & =0.727\end{aligned}$ & $\begin{aligned} \tau_{0} & =1.380 \\
k & =0.499 \\
n & =0.710\end{aligned}$ & $\begin{array}{l}\tau_{0}=1.643 \\
k=0.665 \\
n=0.688\end{array}$ & $\begin{aligned} \tau_{0} & =2.641 \\
k & =1.037 \\
n & =0.642\end{aligned}$ & $\begin{aligned} \tau_{0} & =3.281 \\
k & =1.412 \\
n & =0.612\end{aligned}$ \\
\hline
\end{tabular}




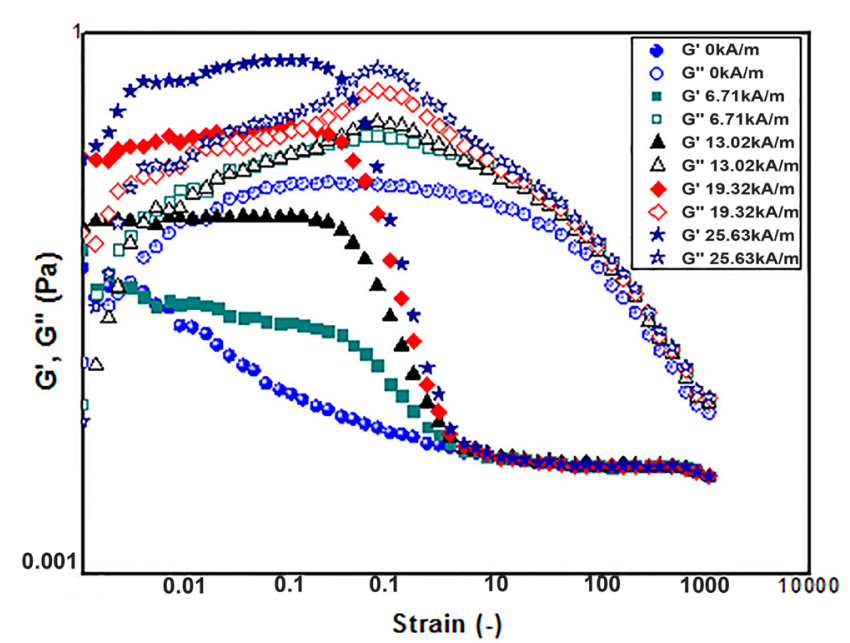

Fig. 10 Variation of elastic and viscous moduli as a function of strain at different magnetic field strength for covered particles dispersed in chitosan $(0.7 \mathrm{v} / \mathrm{v} \%+4.2 \mathrm{~g} / \mathrm{L}$ PDADMAC $+1 \mathrm{wt} \%$ chitosan $)$

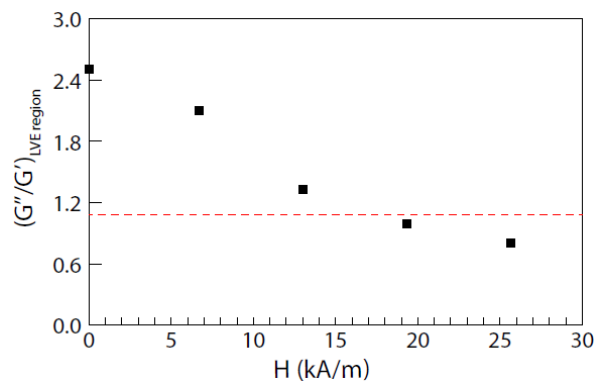

Fig. 11 Variation of the ratio $\left(G^{\prime \prime} / G^{\prime}\right)$ in the Linear Visco-Elastic (LVE) region as a function of magnetic field for covered particles dispersed in chitosan $(0.7 \mathrm{v} / \mathrm{v} \%+4.2 \mathrm{~g} / \mathrm{L}$ PDADMAC $+1 \mathrm{wt} \%$ chitosan $)$

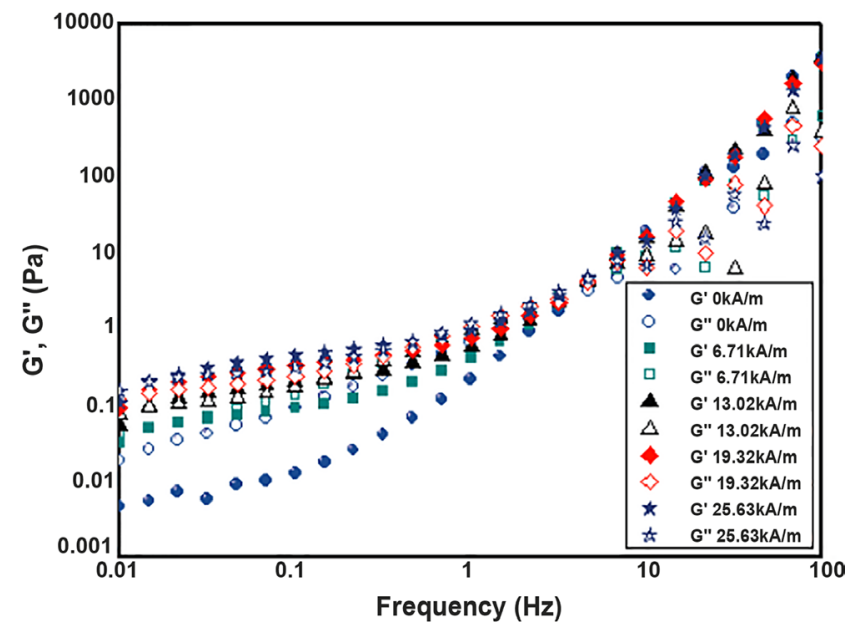

Fig. 12 Variation of elastic and viscous moduli as a function of frequency at different magnetic field strength for covered particles dispersed in chitosan $(0.7 \mathrm{v} / \mathrm{v} \%+4.2 \mathrm{~g} / \mathrm{L}$ PDADMAC $+1 \mathrm{wt} \%$ chitosan $)$

This means that structures formed under magnetic field does not have enough time to relax from high frequencies.

\subsection{Magnetic hydrogel}

From Fig. 13 it is clear that the variation of viscous modulus by elastic modulus decreases as function of time for all the frequencies. These curves are typical of rheological behavior of magnetic hydrogels and their intersection defines the time of gelation.

Applying high field strength on ferrogel having a higher iron oxide content $(1.0 \mathrm{v} / \mathrm{v} \%)$ causes an instantaneous gelation. Rheological study of sol-gel transition for $H=19.32$ and $25.63 \mathrm{kA} / \mathrm{m}$ was therefore impossible.

As it can be seen from Table 5 the gelation time decreases with increasing magnetic field strength for both samples. The higher the magnetic field is, the faster the material is structured. In other words increasing $H$ cause a rapid move from liquid to solid state, this can be confirmed by the decrease in relaxation exponent, meaning that the resulting ferrogels have an elastic behavior.

Generally, $\Delta$ values lie between 0 (elastic gel) and 1 (viscous gel). These limit values at $t g$ are associated to elementary mechanical behavior of a solid Hook for $\Delta=0$ and a Newton fluid for $\Delta=1$ [32].

Moreover results shown by the stiffness of the gel $S$ reflects the viscoelasticity of the system and gives information about the strength of the gel, low values characterize a soft gel while high values indicate a rigid gel. Thus, the increase in $S$ signifies a phase transition from soft gel state to rigid one.

By comparing the rheological parameters of the prepared ferrogels based $1.3 \mathrm{wt} \%$ of chitosan, we find

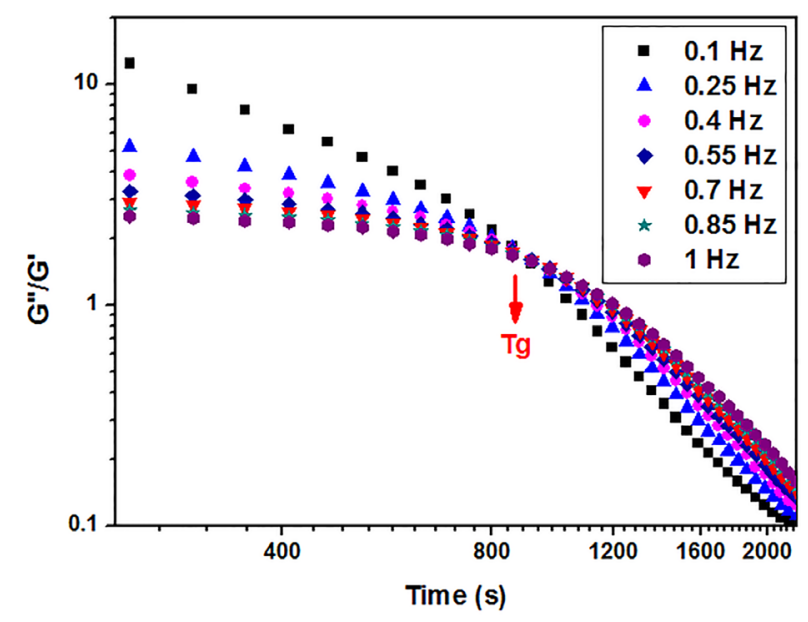

Fig. 13 Variation of the ratio of viscous modulus $G^{\prime \prime}$ by elastic modulus $G^{\prime}$ as a function of time for magnetic hydrogel $(0.7 \mathrm{v} / \mathrm{v} \%$ Particles $+4.2 \mathrm{~g} / \mathrm{L}$ PDADMAC $+1.3 \mathrm{wt} \%$ Chitosan $)$ in the vicinity of the gelation time for different frequencies 
Table 5 Rheological parameters of two magnetic hydrogels

\begin{tabular}{|c|c|c|c|c|}
\hline Sample & $H(\mathrm{kA} / \mathrm{m})$ & $\operatorname{tg}(\mathrm{s})$ & $\Delta$ & $S\left(\mathrm{~Pa} \cdot \mathrm{s}^{\Delta}\right)$ \\
\hline \multirow{4}{*}{$0.7 \mathrm{v} / \mathrm{v} \%$ Particles $+4.2 \mathrm{~g} / \mathrm{L}$ PDADMAC $+1.3 \mathrm{wt} \%$ Chitosan } & 0 & $2019 \pm 100$ & $0.71 \pm 0.01$ & $0.32 \pm 0.10$ \\
\hline & 13.02 & $855 \pm 40$ & $0.67 \pm 0.01$ & $0.37 \pm 0.10$ \\
\hline & 19.32 & $836 \pm 60$ & $0.64 \pm 0.01$ & $0.38 \pm 0.20$ \\
\hline & 25.63 & $809 \pm 70$ & $0.63 \pm 0.01$ & $0.51 \pm 0.20$ \\
\hline \multirow{2}{*}{$1 \mathrm{v} / \mathrm{v} \%$ Particles $+6 \mathrm{~g} / \mathrm{L}$ PDADMAC $+1.3 \mathrm{wt} \%$ Chitosan } & 0 & $1539 \pm 80$ & $0.70 \pm 0.01$ & $0.25 \pm 0.01$ \\
\hline & 13.02 & $784 \pm 100$ & $0.69 \pm 0.01$ & $0.28 \pm 0.02$ \\
\hline
\end{tabular}

that adding maghemite particles to chitosan hydrogel or increasing maghemite content in chitosan ferrogel from $0.7 \mathrm{v} / \mathrm{v} \%$ to $1.0 \mathrm{v} / \mathrm{v} \%$ reinforces ferrogel structure, to cause a rapid sol-gel transition and therefore gelation time decreases from $3550 \pm 150$ to $2019 \pm 100$ for chitosan hydrogel, and from $2019 \pm 100$ to $1539 \pm 80$ for magnetic chitosan hydrogel (ferrogel).

\section{Conclusion}

In this study, rheological properties of magnetic chitosan hydrogel were studied before and after the gelation process, under the effect of magnetic field. The synthesized material was prepared using the blending method. Maghemite particles were functionalized with (Polydiallyldimethylammonium

\section{References}

[1] Li, Y., Huang, G., Zhang, X., Li, B., Chen, Y., Lu, T., Lu, T. J., Xu, F. "Magnetic Hydrogels and Their Potential Biomedical Applications", Advanced Functional Materials, 23(6), pp. 660-672, 2013.

https://doi.org/10.1002/adfm.201201708

[2] Xie, M., Zhang, F., Peng, H., Zhang, Y., Li, Y., Xu, Y., Xie, J. "Layer-by-layer modification of magnetic graphene oxide by chitosan and sodium alginate with enhanced dispersibility for targeted drug delivery and photothermal therapy", Colloids and Surfaces B: Biointerfaces, 176, pp. 462-470, 2019.

https://doi.org/10.1016/j.colsurfb.2019.01.028

[3] Ceylan, H., Yasa, I. C., Yasa, O., Tabak, A. F., Giltinan, J., Sitti, M. "3D-Printed Biodegradable Microswimmer for Theranostic Cargo Delivery and Release", ACS Nano, 13(3), pp. 3353-3362, 2019. https://doi.org/10.1021/acsnano.8b09233

[4] Sudame, A., Kandasamy, G., Maity, D. "Single and Dual Surfactants Coated Hydrophilic Superparamagnetic Iron Oxide Nanoparticles for Magnetic Fluid Hyperthermia Applications", Journal of Nanoscience and Nanotechnology, 19(7), pp. 3991-3999, 2019.

https://doi.org/10.1166/jnn.2019.16326

[5] Yang, H.-M., Hong, S. B., Park, C. W., Lee, K.-W., Choi, Y. S., Yu, J.-H., Seo, B.-K., Moon, J.-K. "Magnetic Adsorbents Embedded in Hydrogel Bead for Surface Decontamination", Journal of Nanoscience and Nanotechnology, 16(8), pp. 8569-8574, 2016.

https://doi.org/10.1166/jnn.2016.12493 chloride, PDADMAC). The exact quantity of PDADMAC needed to cover the entire surface of $\gamma-\mathrm{Fe}_{2} \mathrm{O}_{3}$ was determined by Electrophoretic mobility. Flow measurements showed that magnetic field causes a deviation from Newtonian to Non-Newtonian behavior for bare particles, while covered particles kept the same shear thinning behavior in absence and presence of magnetic strength. Applying magnetic field strengthens the microstructure of the system and that was confirmed by the increase of effective viscosity MagnetoViscous Effect (MVE), the storage modulus and loss modulus in the LVE region.

Mechanical spectroscopy demonstrated that the gelation time of magnetic hydrogel depends on both iron oxide content and magnetic field.

[6] Kondo, A., Fukuda, H. "Preparation of thermo-sensitive magnetic hydrogel microspheres and application to enzyme immobilization", Journal of Fermentation and Bioengineering, 84(4), pp. 337-341, 1997.

https://doi.org/10.1016/S0922-338X(97)89255-0

[7] Bonhome-Espinosa, A. B., Campos, F., Rodriguez, I. A., Carriel, V., Marins, J. A., Zubarev, A., Duran, J. D. G., Lopez-Lopez, M. T. "Effect of particle concentration on the microstructural and macromechanical properties of biocompatible magnetic hydrogels", Soft Matter, 13(16), pp. 2928-2941, 2017.

https://doi.org/10.1039/C7SM00388A

[8] Liu, Z., Liu, J., Cui, X., Wang, X., Zhang, L., Tang, P. "Recent Advances on Magnetic Sensitive Hydrogels in Tissue Engineering", Frontiers in Chemistry, 8, Article number: 124, 2020. https://doi.org/10.3389/fchem.2020.00124

[9] Zhang, J., Huang, Q., Du, J. "Recent advances in magnetic hydrogels", Polymer International, 65(12), pp. 1365-1372, 2016.

https://doi.org/10.1002/pi.5170

[10] Miyazaki, T., Iwanaga, A., Shirosaki, Y., Kawashita, M. "In situ synthesis of magnetic iron oxide nanoparticles in chitosan hydrogels as a reaction field: Effect of cross-linking density", Colloids and Surfaces B: Biointerfaces, 179, pp. 334-339, 2019. https://doi.org/10.1016/j.colsurfb.2019.04.004

[11] Hernández, R., Zamora-Mora, V., Sibaja-Ballestero, M., VegaBaudrit, J., López, D., Mijangos, C. "Influence of iron oxide nanoparticles on the rheological properties of hybrid chitosan ferrogels", Journal of Colloid and Interface Science, 339(1), pp. 53-59, 2009. https://doi.org/10.1016/j.jcis.2009.07.066 
[12] Villamin, M. E., Kitamoto, Y. "Influence of $\mathrm{pH}$ on Dynamic Magnetic Susceptibility of Iron-Oxide Nanoparticles in a Chitosan Hydrogel Matrix", IEEE Transactions on Magnetics, 55(2), pp. 1-4, 2019.

https://doi.org/10.1109/TMAG.2018.2869828

[13] Zhang, S., Zhai, Y., Zhang, Z. "Preparation and properties of magnetic scensitive hydrogel", In: International Conference on Electronic and Mechanical Engineering and Information Technology, Harbin, China, 2011, pp. 4482-4484.

https://doi.org/10.1109/EMEIT.2011.6024024

[14] Brugnerotto, J., Lizardi, J., Goycoolea, F. M., ArgüellesMonal, W., Desbrières, J., Rinaudo, M. "An infrared investigation in relation with chitin and chitosan characterization", Polymer, 42(8), pp. 3569-3580, 2001. https://doi.org/10.1016/S0032-3861(00)00713-8

[15] Massart, R. "Preparation of aqueous magnetic liquids in alkaline and acidic media", IEEE Transactions on Magnetics, 17(2), pp. 1247-1248, 1981. https://doi.org/10.1109/TMAG.1981.1061188

[16] Galindo-Gonzalez, C., Ponton, A., Bee, A., Chevalet, J., Talbot, D., Perzynski, R., Dubois, E. "Investigation of water-based and oilbased ferrofluids with a new magnetorheological cell: effect of the microstructure", Rheologica Acta, 55(1), pp. 67-81, 2016. https://doi.org/10.1007/s00397-015-0892-5

[17] Winter, H. H., Chambon, F. "Analysis of Linear Viscoelasticity of a Crosslinking Polymer at the Gel Point", Journal of Rheology, 30(2), pp. 367-382, 1986. https://doi.org/10.1122/1.549853

[18] Malvern Instruments Ltd. "Zetasizer Nano Series User Manual", Malvern Instruments Ltd., Malvern, Worcestershire, UK, MAN0317, Issue 1.1, 2004.

[19] Mezger, T. G. "The Rheology Handbook: For users of rotational and oscillatory rheometers", Vincentz Verlag, Hannover, Germany, 2002.

[20] Herschel, W. H., Bulkley, R. "Konsistenzmessungen von GummiBenzollösungen" (Consistency measurements of rubber-benzene solutions), Kolloid-Zeitschrift, 39(4), pp. 291-300, 1926. (in German) https://doi.org/10.1007/BF01432034

[21] Genc, S., Derin, B. "Synthesis and rheology of ferrofluids: a review", Current Opinion in Chemical Engineering, 3, pp. 118-124, 2014. https://doi.org/10.1016/j.coche.2013.12.006

[22] Afifah, A. N., Syahrullail, S., Sidik, N. A. C. "Magnetoviscous effect and thermomagnetic convection of magnetic fluid: A review", Renewable and Sustainable Energy Reviews, 55, pp. 1030-1040, 2016.

https://doi.org/10.1016/j.rser.2015.11.018
[23] Odenbach, S., Thurm, S. "Magnetoviscous Effects in Ferrofluids", In: Ferrofluids, Springer, Berlin, Heidelberg, Germany, 2002, pp. 185-201. https://doi.org/10.1007/3-540-45646-5_10

[24] Lopez-Lopez, M. T., Kuzhir, P., Zubarev, A. "Effect of drop-like aggregates on the viscous stress in magnetic suspensions", Journal of Non-Newtonian Fluid Mechanics, 208-209, pp. 53-58, 2014. https://doi.org/10.1016/j.jnnfm.2014.04.001

[25] Odenbach, S., Raj, K. "The Influence of Large Particles and Agglomerates on the Magnetoviscous Effect in Ferrofluids", Magnetohydrodynamics, 36(4), pp. 312-319, 2000.

[26] Ren, Y., Ellis, P. R., Ross-Murphy, S. B., Wang, Q., Wood, P. J. "Dilute and semi-dilute solution properties of $(1 \rightarrow 3),(1 \rightarrow 4)-\beta$-D-glucan, the endosperm cell wall polysaccharide of oats (Avena sativa L.)", Carbohydrate Polymers, 53(4), pp. 401-408, 2003. https://doi.org/10.1016/S0144-8617(03)00117-6

[27] Fijan, R., Šostar-Turk, S., Lapasin, R. "Rheological study of interactions between non-ionic surfactants and polysaccharide thickeners used in textile printing", Carbohydrate Polymers, 68(4), pp. 708-717, 2007. https://doi.org/10.1016/j.carbpol.2006.08.006

[28] Martínez, A., Chornet, E., Rodrigue, D. "Steady-shear Rheology of Concentrated Chitosan Solutions", Journal of Texture Studies, 35(1), pp. 53-74, 2004 https://doi.org/10.1111/j.1745-4603.2004.tb00822.x

[29] El-Hefian, E. A., Elgannoudi, E. S., Mainal, A., Yahaya, A. H. "Characterization of chitosan in acetic acid: Rheological and thermal studies", Turkish Journal of Chemistry, 34(1), pp. 47-56, 2010. https://doi.org/10.3906/kim-0901-38

[30] Brack, H. P., Tirmizi, S. A., Risen Jr, W. M. "A spectroscopic and viscometric study of the metal ion-induced gelation of the biopolymer chitosan", Polymer, 38(10), pp. 2351-2362, 1997. https://doi.org/10.1016/S0032-3861(96)00780-X

[31] Roberts, G. A., Taylor, K. E. "Chitosan gels, 3. The formation of gels by reaction of chitosan with glutaraldehyde", Die Makromolekulare Chemie / Macromolecular Chemistry and Physics, 190(5), pp. 951-960, 1989. https://doi.org/10.1002/macp.1989.021900504

[32] Payet, L., Ponton, A., Agnely, F., Colinart, P., Grossiord, J. L. "Caractérisation rhéologique de la gélification d'alginate et de chitosane: effet de la température" (Temperature effect on the gelation kinetics of chitosan and alginate studied with rheology), Rhéologie, 2, pp. 46-51, 2002. (in French) 